\title{
Controlling the Data Warehouse - a Balanced Scorecard Approach
}

\author{
Frank Bensberg \\ Department of Information Systems, University of Muenster, Germany
}

\begin{abstract}
Data warehouse systems have become a basic technological infrastructure in management decision making. Nevertheless, the overall utility of data warehouses remains unmeasured in most practical cases. As a consequence of this, IT-managers do not possess appropriate means to evaluate warehouse benefits in order to decide about investments in warehousing technology.

This paper develops a controlling instrument for data warehouse systems based on the Balanced Scorecard (BSC) approach. On the basis of the technological aspects of data warehouse systems, the BSC perspectives are developed and populated with relevant objectives and measures for data warehouse success. These perspectives are integrated into a consistent data warehouse scorecard. Finally, this instrument provides a holistic approach to drive the performance of data warehouse systems.
\end{abstract}

Keywords: data warehouse, balanced scorecard, controlling, performance measurement, strategic management.

\section{Introduction}

In the last decade, the data warehouse concept has experienced great acceptance. The primary reason for building data warehouses is to improve information quality in order to achieve specific business objectives such as competitive advantage or enhancing decision making. According to [18], the annual expenses for a data warehouse with 1 terabyte raw data sum up to 5.3 million US-dollar, where costs for IT-staff and IT-services dominate. In most cases, the data warehouse budget consumes a significant part of the total IT-budet and therefore cost justification is a conditio sine qua non.

Though many organizations have experienced problems with implementing data warehouse systems [12], these are mostly not subject to detailed analysis of costs and benefits [3]. There- fore, a dedicated controlling instrument is necessary which is able to track data warehousing success and to steer investments in data warehousing technology. Since data warehouse benefits are predominantly intangible and calculation of the return on investment (ROI) of data warehousing is in most cases infeasible [23], it is necessary to evaluate data warehouse expenditures from both financial and non-financial views. To achieve this objective, it seems reasonable to examine the balance scorecard concept for the domain of data warehousing.

From a research position, it is interesting to see that the balanced scorecard approach has been applied to different areas of information technology. In [5], the development of a balanced IT scorecard for software producing business units is realized. Further scorecard-related publications deal with performance measurement of ERP-software (e.g. [16] and [14]) or creation of generic IT-scorecards which apply to an IT-department as a whole (e.g. [19], [20]). However, no effort has been made in order to adapt the balance scorecard to the domain of data warehousing. This seems necessary since these systems are supremeley strategic and implementation failure rates are high $([23],[2])$. Consequently, data warehouse systems deserve closer attention by IT-controlling in order to sucessfully support business strategy.

To create an appropriate controlling instrument for data warehouses, this paper first discusses basic technical and organizational characteristics of data warehouse systems. Afterwards, the balanced scorecard concept is introduced and applied to the domain of data warehousing. This is achieved by identifying relevant objectives and measures for each scorecard perspec- 
tive. Finally, the perspectives are merged into a conceptual data warehouse scorecard and aspects of integration into strategic management are concluded.

\section{The Data Warehouse Concept}

\subsection{Data Warehouse Architecture}

According to INMON, a data warehouse is a subject-oriented, integrated, non-volatile, and time-variant collection of data which serves as an infrastructure for management decisions (see [6], p. 33). This dispositive data collection is based on operational data stores (e.g. enterprise resource planning systems like SAP R/3), but is arranged according to analytical interests and is therefore not dependent on operational business processes. The high practical acceptance of the data warehouse concept is a result of the grown architecture of operational information systems. Since these systems are built in order to achieve a high rate of transactions, generation of decisive management information imposes a number of technical and conceptual problems (see [7], p. 42-43).

In order to keep data warehouse content up to date, it is necessary to establish a technological infrastructure which extracts relevant data from the operational information systems and consolidates these data within a well documented database system. Consequently, the data in the data warehouse is made up of snapshots of the enterprise's multiple operational databases. The resulting data warehouse architecture is depicted in Fig. 1.

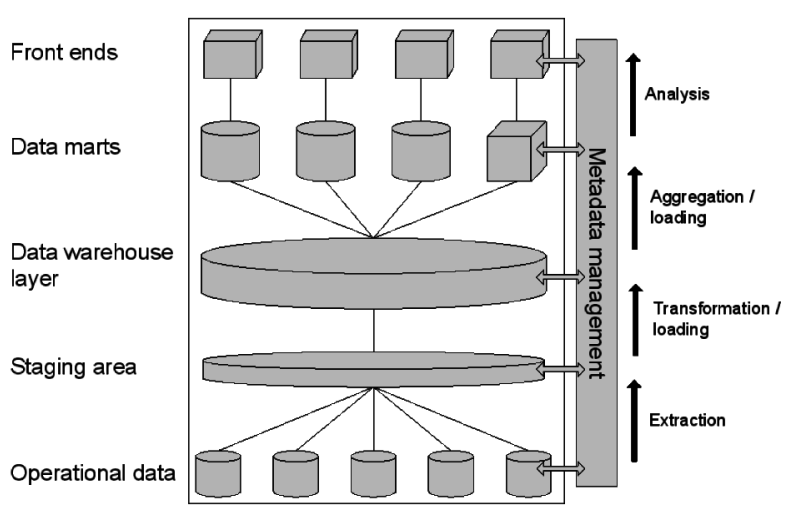

Fig. 1. The architecture of a data warehouse system.
This architecture consists of core components and processes which constitute a complex analytical information system. The bottom layer of the warehouse is connected to the data stores of operational information systems (e.g. accounting, sales, human ressources) in order to extract relevant data which are pooled into a staging area. In addition to this, external data (e.g. from market research institutes or financial services) can be acquired to complete the data needed for management decisions. The staging area serves as a temporary data store and allows the consolidation of data from heterogenous sources. A typical transformation task is to remove homonyms (e.g. using an identical label for different types of attributes) and synonyms (e.g. using two different labels for an attribute). As a result, the integrated data is loaded into a central data warehouse layer which is typically normalized in order to avoid redundancies. These early tasks of the data warehouse process are executed by use of ETL-tools (extraction, transformation, loading). These tools provide connectivity to a broad set of different data storage formats (e.g. different database systems like Oracle, DB2 or SQL Server or different text file formats).

In order to turn warehouse data into decisive information, it must be tailored to the needs of the end users located in different organizational units (e.g. functional departments). Typically, the informational needs of the marketing department differ from those of the accounting department. As a consequence of this, specific departmental views on the data have to be created. These views, which are called data marts, can be further customized in order to comply with the informational needs of single users (e.g. a specific salesperson in a defined region).

To get information from these data marts, end users are provided with a set of tools which allow analytical processing. Most common are report generation tools which support simple aggregations (e.g. calculation of statistical measures like mean values, etc.). In order to provide interactive analysis with user-defined views, OLAP tools are frequently used. While report generation tools and OLAP provide more or less simple analytical operations, data mining tools permit the analysis of complex patterns $([4]$, p. 9). For instance, data mining tools can 
reveal buying patterns of customers, which can be used to optimize marketing campaigns.

\subsection{Organizational Implications}

High complexity of data warehouse systems evolves from the fact that these systems have to be tailored to the specific requirements of the organization and cannot be set up out of the box. First, the data warehouse has to be built upon a given data infrastructure which has grown historically in most organizations. This multitude of heterogenous data sources requires a high number of interfaces which must be continuously managed in order to keep data warehouse content up to date. Besides these technological dependencies, another source of complexity evolves from the end users of data warehouse services and their different tasks. Managerial decisions are carried out by numerous managers at very different hierarchical and departmental levels. Consequently, informational needs of functional area management and executive management differ significantly and lead to a high degree of specifity in information demand. Since an uncertain business environment with increasingly intense competition also implies dynamically evolving informational needs, data warehouse systems have to be flexible in order to comply with future requirements. Facing numerous technological and organizational dependencies, this flexibility is crucial for successful data warehouse evolution.

As the implementation and proliferation of a data warehouse is commonly a strategic goal, it is necessary to link data warehouses directly to business strategy. A very popular instrument for transforming strategy into action is the balanced scorecard, which has originally been introduced by KAPLAN and NORTON at the enterprise level (see [8], [9], [10], [11]).

\section{Balanced Scorecard as a Strategic Controlling Instrument}

The BSC has been developed in order to provide a controlling instrument which does not merely focus on financial measures, but furthermore considers non-financial measures. These measures reflect relevant organizational objectives which ensure strategy implementation. This approach is based on the experience that a singular focus on financial metrics reduces the quality of strategic decisions and therefore is not adequate to align business processes to strategy. The BSC suggests to measure organizational performance in four key areas which are depicted in Fig. 2.

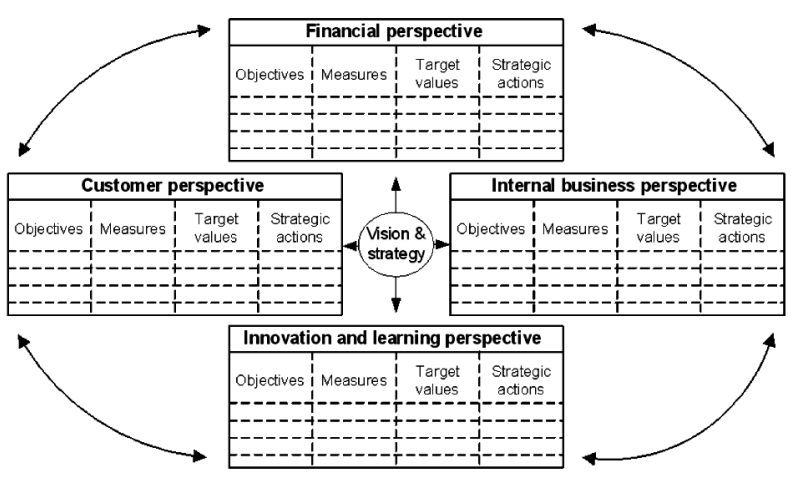

Fig. 2. The basic model of the BSC.

Each perspective consists of strategic objectives which are derived from business strategy and are linked to specific measures. In order to use the BSC in business planning, the target values for each measure have to be defined and connected to corresponding actions which will ensure achievement of the prospected value.

The financial perspective describes measures which are important to the shareholders of a corporation and reflect growth and profitability. Typical measures used for this perspective include sales, return on investment, and cash flow. They reflect strategic objectives like corporate survival or corporate success and depend on non-financial performance measures of other perspectives.

The BSC suggests that organizations have to identify the market segments that they plan to supply. For each target segment measures have to be defined which reflect the organizational performance from the market point of view. In general, measures like market share, customer retention, frequency of orders, and number of new customers are commonly used in order to populate the customer perspective.

Consequently, the internal business processes have to be aligned to support financial and customer-based objectives. This is achieved via the internal business perspective which reflects 
the performance of critical business processes. These processes, which have a significant impact on customer satisfaction or financial measures, can relate to research and development (e.g. time to market of new technologies), production and delivery (e.g. cycle time, product quality), and service (e.g. response time).

All described views of the BSC depend on the innovation and learning perspective. This perspective is based on the assumption that only a learning and innovating organization is able to survive intense competition. Therefore, this perspective measures the innovative potential of the organizational infrastructure like employees and information systems. Commonly used measures are employee satisfaction and information coverage ratio.

In order to implement a BSC for a given organization, it is necessary to start scorecard design at the strategic level of business. Consequently, the strategic business scorecard has to be adapted in a top down mode for subordinated organizational units such as departments, groups, projects and individuals. Finally, the BSC has to be cascaded throughout the organization to ensure goal alignment at every level. As a result of this, the BSC becomes a communication tool revealing the strategy of the organization via a set of well-defined objectives and measures. These relate to each other through cause-effect-chains (e.g. employee satisfaction influences product quality).

\section{Development of a Data Warehouse Balanced Scorecard}

\subsection{Organizational Prerequisites}

In order to develop a data warehouse balance scorecard, it is necessary to define the organizational environment. The development and operation of a data warehouse system is most commonly realized by a corporation's information technology department (IT-department) which also is responsible for operational systems (e.g. ERP-systems) and other IT-resources. In order to guarantee an economic use of information technology, it is reasonable to run ITdepartments as profit centers. This means that the IT-department offers products for internal and external customers. Internal customers (e.g. functional departments) are entitled to decide freely if they buy IT-related services from the internal IT-department or from external suppliers. Of course, the IT-department has to define transfer prices for each IT-related product offered on the internal market.

Consequently, the operation of a data warehouse system leads to information products which are offered to customers. There is a broad spectrum of different services which can be offered by an IT-department based on the warehousing platform:

- reporting services (definition of reports, report creation and delivery),

- OLAP-services (definition and delivery of OLAP data marts and frontends to end users),

- data mining services (definition and execution of data mining tasks, presentation and deployment of results), and

- data quality management services.

If the IT-department is run as a profit center, these information products are subject to the transfer price regime of the organization. Consequently, end users have to pay these transfer prices for usage of data warehouse services. These prerequisites form the organizational framework for further data warehouse BSC development.

\subsection{The Financial Perspective}

The financial perspective of the data warehouse BSC has to reflect the contribution of a data warehouse to the profitability of the IT-department. Relevant measures are the sales generated by data warehouse-related end user services provided to internal customers. Since profit center organizations are also entitled to serve external customers, it is necessary to differentiate between internal and external sales. External sales could be generated by providing high quality address data for mailing purposes or consulting services for external data warehousing projects. Nevertheless, it should be assured that the ratio of internal to external sales is well-balanced in order to provide an incentive for warehouse management to serve both 
groups of customers. This can be measured via the sales mix as a ratio of internal to external sales.

In addition to sales, the costs of the warehouse system are also relevant for the financial perspective. A basic phenomenon of data warehousing is that predominantly fixed costs are allocated. Therefore, it is impossible to trace down data warehousing costs to originating costing units.

Since a significant portion of IT-related costs are commonly hidden costs, it seems reasonable to adopt a total cost of ownership approach in order to assess the effectiveness of an organization's IT expenditures [17]. According to this, it is necessary to differentiate between direct and indirect costs. Direct costs are budgeted costs for hard- and software, operation, and administration. According to [18], the following types of direct costs have to be considered for data warehouse systems:

- data warehouse platform,

- ETL-platform,

- database and miscellaneous software,

- IT-staff and services, and

- support and maintenance.

In contrast to this, indirect costs are non-budgeted costs which are caused by inefficient system operations or usage. Indirect costs may spring from unplanned data warehouse downtime which impedes managerial decisions to be taken and

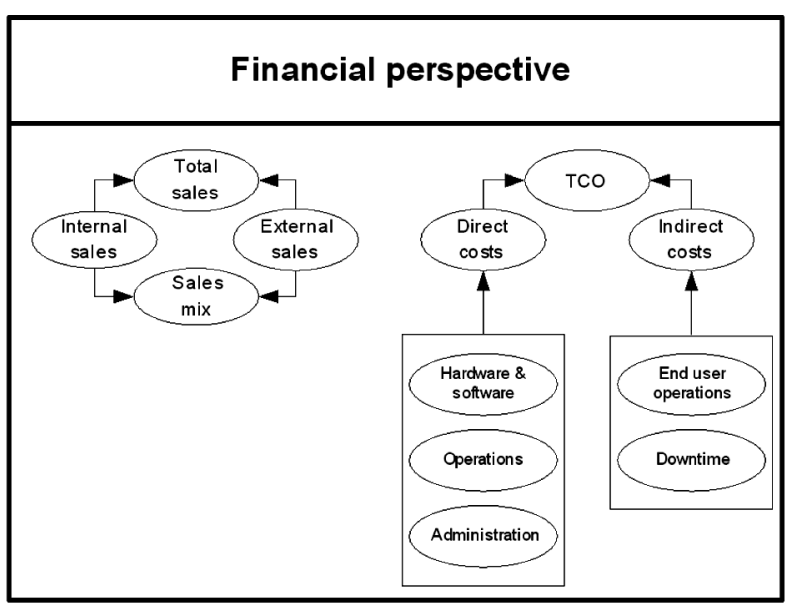

Fig. 3. The financial perspective. therefore decreases productivity of management processes. Moreover, another driver of indirect costs are inefficient end users' operations. For instance, it is not efficient that end users carry out tasks that should be done by dedicated IT staff.

In order to complete the financial perspective, it is necessary to integrate all components of this sales and cost framework into the financial perspective as shown in Fig. 3.

\subsection{The Customer Perspective}

In order to define the customer perspective of the data warehouse BSC, the internal and external customer(s) of the data warehouse-related services have to determined first. As far as end user-oriented analytical services like reporting, OLAP and data mining are concerned, predominantly managers at different departmental levels are the primary segment of relevant internal customers (e.g. executive managers and functional area managers). For this segment, a common strategic objective is to become preferred provider of managerial information. In order to evaluate the achievement of this objective, coverage of the data warehouse-related information products has to be measured. Possible measures for this information coverage are the percentage of business decisions covered or the percentage of managerial positions supplied with data warehouse-related information products. In addition to this, the percentage of operational systems whose data are processed by the data warehouse may be another relevant measure.

Additionally, it seems necessary to measure end user satisfaction with the data warehouse-related information products. This can be evaluated via surveys permitting the calculation of a customer satisfaction index, and behavioral data (e.g. log files) which reveal patterns of information usage (e.g. frequency and duration of use). The resulting customer perspective for this segment is shown in Fig. 4.

Internal customers for data warehouse-related services do not only exist at the managerial level, but at the operational level too. Since operational information systems frequently suffer 


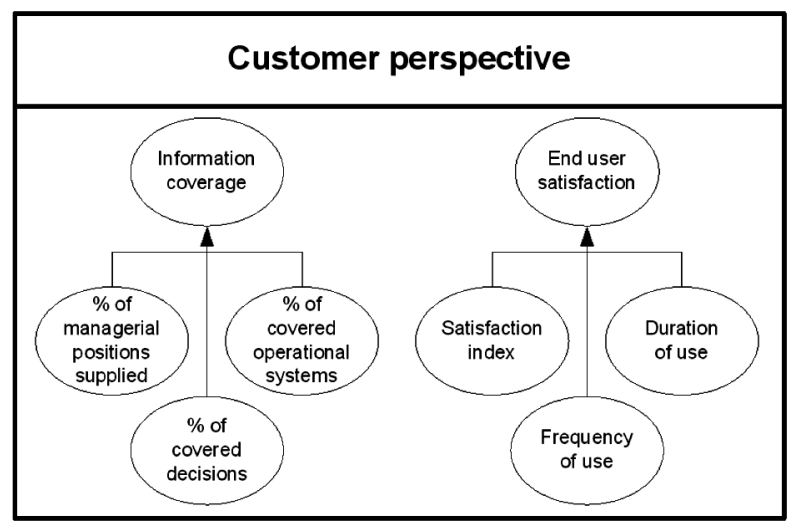

Fig. 4. The customer perspective.

from poor data quality [13] and source data quality problems generally become evident once the data are loaded into the warehouse [15], the service of a data warehouse environment is to provide data quality management services. For instance, during the ETL-process of data warehousing duplicates in operational data stores can be identified and properly removed. These cleaned data can be provided to the operational level in order to reduce data quality problems. For this segment, the strategic objective of a data warehouse is to become preferred provider of data quality management services. The internal market share of this service could be measured as percentage of operational systems supplied with cleaned data. In the long run, this proportion could decrease over time if data warehouse services persistently enhance the data quality of operational systems.

For very different data warehouse-related services external customers may also exist. For example, cleaned address data can be extracted from the data warehouse and optimized for different marketing purposes. These addresses could be provided to affiliated or cooperating companies. A strategic objective for this segment could be to become preferred mailing address supplier. In order to measure the achievement of this objective, the number of addresses sold can be quantified.

\subsection{The Internal Business Perspective}

The internal business perspective focuses on the internal conditions for satisfying the customer supplied with the data warehouse's services.
Since the internal processes of a data warehouse primarily serve to provide appropriate information for managerial decisions, measures are necessary which reflect information quality. In literature, there are many approaches which can be applied to information quality [22]. According to [1] (p. 142), information quality characteristics belong to two categories: inherent and pragmatic information quality characteristics. The former are independent of the processes that use the data for specific business purposes and indicate static quality characteristics:

- Completeness of values. This characteristic is measured as the degree to which values are present in the data warehouse and are not missing.

- Accuracy to reality or a surrogate source. This criterion reflects the degree to which a data value in the data warehouse conforms to reality or an original source of data (like a document or a form).

- Accessibility characterizes the ability to access the information within a data warehouse when it is required. Consequently, this criterion does reflect if the data warehouse does contain corresponding information.

Pragmatic information quality characteristics describe the appropriateness of information for special business tasks:

- Relevance. This criterion describes the necessity of information for business decisions. It can be measured empirically by observing end user behavior in relation to the data. If data objects are not used at all, they may be irrelevant for business decisions.

- Timeliness of information. In order to ensure a responsive supply of information, it is necessary to deliver it in time. This criterion could be measured as the percentage of information retrieval processes performed within the desired time frame.

- Interpretability. Information can be efficiently used for decision processes only if 
it is easy to interpret, e.g. by use of visualization techniques. Consequently, this criterion can be subjectiveley measured as the degree to which information is directly usable for decision purposes.

In literature, a vast multitude of different information quality criteria are proposed ([22], [21]). In practical application domains these should be selected according to situational requirements in order to meet the specific informational needs of the management. Due to the relevance of information quality for warehouse success, it could be reasonable to integrate these metrics into a dedicated information quality perspective.

In addition to these dedicated information quality criteria, general availability of data warehouse services influences end user acceptance and indirect TCO caused by downtime. As a consequence of this, general performance measures such as average system availability, average downtime, and average response time, play an important role. The resulting internal business perspective is shown in Fig. 5.

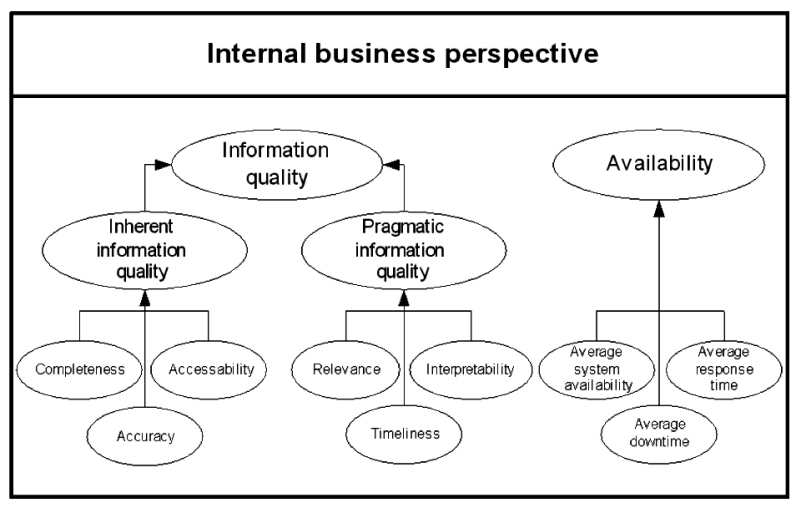

Fig. 5. The internal business perspective.

\subsection{The Innovation and Learning Perspective}

This perspective has to reflect the flexibility to meet actual and future requirements. Technical flexibility stems from software and hardware platforms used for data warehouse implementation. A key factor of future flexibility is vendor reliability. This can be measured by the number of stable releases per year which can productively be used without major changes. In addition, the compliance to relevant standards, conventions or legal regulations is another major driver for warehouse adaptability. This issue can be measured inversely by the number of standards the data warehouse system fails to comply to (see [21], p. 2.24). Another relevant factor for technical flexibility is interoperability of data warehousing components. This measure quantifies the number of information systems the data warehouse is able to interact with (see [21], p. 2.24).

The organizational flexibility of a data warehouse is predominantly driven by the qualification of employees. This particularly refers to the technical data warehousing staff who must have adequate business knowledge in order to communicate and to understand end users informational needs [23]. As a measure of qualification, experience with similar projects can be taken into account. In addition, warehousing staff has to keep pace with technical development. This can be measured by the number of training days per employee. In order to strengthen end users' involvement, adequate training has to be provided, metered as number of training days per end user. Of course, this measure influences indirect TCO in terms of inefficient self-support or peer-to-peer-support. According to WATSON and HALEY, it is of vital importance to provide appropriate meta data, such that end users are enabled to search and identify relevant data ([23], p. 36). Consequently, it is necessary to measure the degree to which data warehouse processes and entities are documented.

The resulting innovation and learning perspective is depicted in Fig. 6.

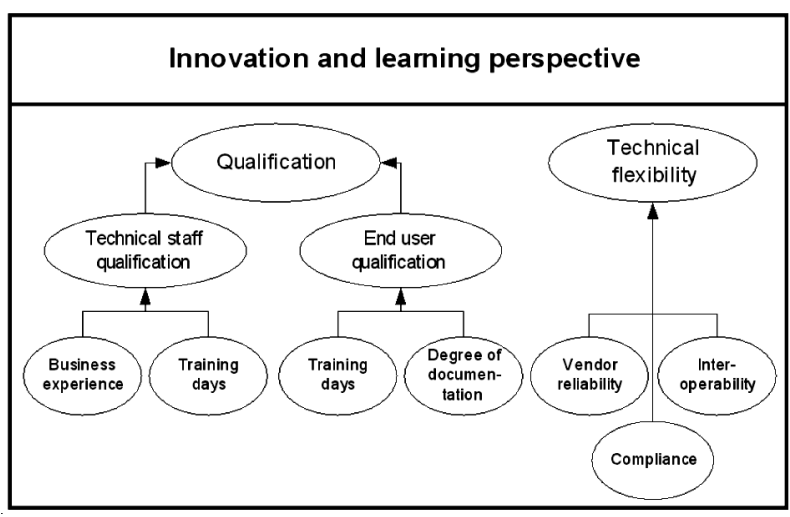

Fig. 6. The innovation and learning perspective. 


\section{Conclusion}

This paper proposed a balanced scorecard framework which can be used by IT-departments to plan and control data warehouse systems in a profit center organization. Each perspective of the balanced scorecard was supplied with adequate objectives and measures, such that the resulting framework represents a holistic approach. The data warehouse BSC can be used as a strategic IT-management tool in order to check performance based on the objectives that have been defined in advance. All perspectives of the resulting scorecard are depicted in Fig. 7. This figure also reveals cause-effect-chains which exist between major measures.

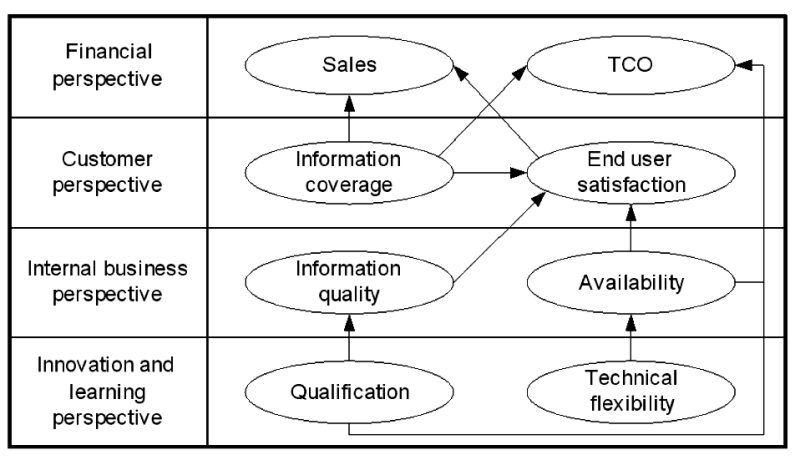

Fig. 7. The data warehouse BSC.

In practice, the proposed framework has to be associated with corporate strategy. If a corporate scorecard already exists, the data warehouse scorecard has to conform to corporate objectives. In particular, it has to be determined if there are corporate objectives the data warehouse can directly influence. If there is a strategic objective like "Increase competitive advantage by using information technology to focus on premium customers", the data warehouse BSC has to translate this directive into local objectives. For instance, a resulting objective for the customer perspective could be: "Integrate and supply value-based customer information for sales \& marketing activities".

Besides, for a data warehouse BSC it is necessary to conform to other scorecards developed for the IT-department. In [20], a scorecard cascade is proposed which derives a strategic ITBSC from the corporate BSC. Furthermore, the strategic IT-BSC is divided into a development
BSC and a operational BSC. For a data warehouse system this approach does not seem to be reasonable. This is because data warehousing systems do not conform to traditional development models of software engineering which strictly differentiate between development and operation. Consequently, it seems more successful to link the data warehouse BSC directly to the strategic IT-BSC.

According to data warehouse research literature, most of the measures presented in this paper represent critical success factors (see [3], $[15],[2],[23],[21])$ that have been identified in practical success and failure studies. Therefore, this framework can be used as conceptual blueprint for the development of customized data warehouse BSCs in practical application contexts. These will play an important role in further research evaluating the effectiveness of the BSC approach to drive data warehouse performance.

\section{Acknowledgements}

The author would like to thank Mrs. Christina Reichel at Mummert Consulting AG for insightful discussions on data warehouse engineering. My thanks also go to Mr. Martin Weich and Mr. Volker Manthey at Horváth \& Partners for their helpful experiences on practical balanced scorecard management.

\section{References}

[1] ENGLISH, L.P., Improving Data Warehouse and Business Information Quality, New York: John Wiley \& Sons, 1999.

[2] Frolick, M., Lindsey, K., Critical Factors for Data Warehouse Failure, Journal of Data Warehousing, Vol. 8, No. 1. http://www.dw-insti tute. com/research/display . asp?id=6592 [03/11/2003]

[3] Haley, B., Implementing Successful Data Warehouses, in: Journal of Data Warehousing, Vol. 2 No. 2, 1998, pp. 48-51.

[4] Han, J., Kamber, M., Data Mining - Concepts and Techniques, San Francisco: Morgan Kaufmann Publishers, 2001.

[5] IBANEZ, M., Balanced IT Scorecard Description Version 1.0, European Software Institute (editor), Technical Report ESI-1998-TR-012, May 1998. 
[6] InMON, W.H., Building the Data Warehouse, New York: Wiley, 1996.

[7] JONES, K., An Introduction to Data Warehousing: What Are the Implications for the Network? International Journal of Network Management, Vol. 8, 1998, pp. 42-56.

[8] Kaplan, R.S., Norton, D.P., Putting the Balanced Scorecard to Work, in: Harvard Business Review, Vol. 71, 1993, pp. 134-147.

[9] KaPlan, R.S., NoRTON, D.P., The Balanced Scorecard - Measures that Drive Performance, in: Harvard Business Review, Vol. 70, 1992, pp. 71-79.

[10] KaPlan, R.S., NorTon, D.P., Transforming the Balanced Scorecard from Performance Measurement to Strategic Management: Part II, in: Accounting Horizons, Vol. 15 No. 2, 2001, pp. 147-160.

[11] KAPLAN, R.S., NORTON, D.P., Using the Balanced Scorecard as a Strategic Management System. In: Harvard Business Review, Vol. 74, 1996, pp. 75-85.

[12] Meta Group, Data Warehouse Scorecard, 1999. http: //www.sfdama.org/dwscorecard.pdf [03/10/2003]

[13] Redman. T.C., The Impact of Poor Data Quality on the Typical Enterprise, in: Communications of the $A C M$, Vol. 41 No. 2, pp. 79-82.

[14] Rosemann, M., Wiese, J., Measuring the Performance of ERP Software - a Balanced Scorecard Approach, Proceedings of the $10^{\text {th }}$ Australasian Conference on Information Systems, 1999, pp. 773784.

[15] Sammon, D., Finnegan, P., The Ten Commandments of Data Warehousing, in: The DATA BASE for Advances in Information Systems, Vol. 31 No. 4, 2000, pp. 82-91.

[16] Sedera, D., Gable, G., Rosemann, M., A Balanced Scorecard Approach to Enterprise Systems Performance Measurement, in: Proceedings ot the $12^{\text {th }}$ Australasian Conference on Information Systems, 2001, pp. 573-584.

[17] Smith David, J., Schuff, D., St. Louis, R., Managing Your IT Total Cost of Ownership, Communications of the ACM, Vol. 45. No. 1, pp. 101-106.

[18] Strange, K., Data Warehouse and Business Intelligence: The Challenges of TCO and ROI, Gartner Symposium ITxpo, 2002 October 6-11; Orlando, Florida: Walt Disney World.

[19] VAn Grembergen, W., SAUll, R., Aligning Business and Information Technology through the Balanced Scorecard at a Major Canadian Financial Group: its Status Measured with an IT BSC Maturity Model, Proceedings of $34^{\text {th }}$ Annual Hawaii International Conference on System Sciences, Computer Society Press, 2001, pp. 1-10.

[20] VAn Grembergen, W., The Balanced Scorecard and IT Governance, in: Information Systems Control Journal, Vol. 2, 2000, pp. 40-43.
[21] VASsiliadis, P., Data Warehouse Modeling and Quality Issues, Ph.D. Thesis, Technical Report, Knowledge and Database Systems Laboratory, Dept. of Electrical and Computer Engineering, National Technical University of Athens, Greece, June 2000.

[22] Wang, R.Y., Storey, V.C., Firth, C.P., A Framework for Analysis of Data Quality Research, in: IEEE Transactions on Knowledge and Data Engineering, Vol. 7, No. 4, pp. 623-640.

[23] Watson, H. J., Haley, B., Managerial Considerations with Data Warehousing, in: Communications of the ACM, Vol. 41, No. 9, pp. 32-37.

Received: June, 2003 Accepted: September, 2003

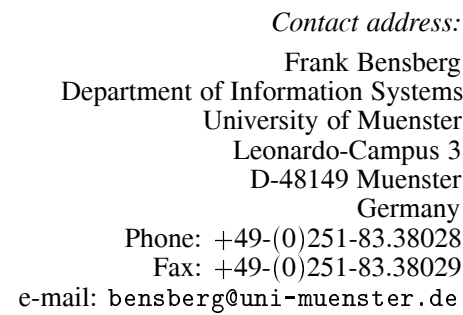

Contact address:

Frank Bensberg

Department of Information Systems

University of Muenster

Leonardo-Campus 3

D-48149 Muenster Germany

Phone: +49-(0)251-83.38028 Fax: +49-(0)251-83.38029 e-mail: bensberg@uni-muenster.de

FRANK BENSBERG studied economics at the University of Muenster. Afterwards, he acquired a doctoral degree for his thesis on Web Log Mining. Since 2000, he is working as scientific assistant at the University of Muenster. His main research interests are controlling and decision support systems, data mining and e-learning. 